\title{
FATIGUE CRACK GROWTH IN INCONEL 718 SUPERALLOY FOIL AT ELEVATED TEMPERATURE
}

\author{
Eddy Vanswijgenhoven and John Holmes \\ Department of Engineering Science and Mechanics, Pennsylvania State University, \\ State College, PA, 16803, U.S.A.
}

\begin{abstract}
Brazed superalloy honeycomb panels with thin high-strength face sheets are under development for the thermal protection system of future reusable launch vehicles. These vehicles use the honeycomb panels as an active and load-bearing part of their primary structure. The panels will be subject to repetitive dynamic stresses, caused by mechanical, thermal and acoustic loading. One of the most important properties with respect to long-term dynamic loading is fatigue crack growth resistance. However, crack propagation in superalloy foils, used in lightweight panels, is still relatively unexplored.

This paper reports on the fatigue crack growth behavior in $250 \mu \mathrm{m}$ thick Inconel 718 foil at RT, $400{ }^{\circ} \mathrm{C}$, and $550^{\circ} \mathrm{C}$. The principal goals of the paper are to describe the technique used for cyclic crack growth rate testing and to report cyclic fatigue crack growth rates at elevated temperature. The relationship between $d a / d N$ and $\Delta K$ obeys the Paris law $d a / d N=C \Delta K^{m}$ but the values measured for the exponent, $m$, are higher than 5 . This is significantly higher than the exponents typically found for fatigue crack growth in thicker Inconel 718 specimens. A possible explanation for the strong increase of the $d a / d N$ with $\Delta K$ is the low fracture toughness of Inconel 718 foil. The measured value for the foil $\left(35 \mathrm{MPa} \mathrm{m}{ }^{1 / 2}\right)$ is less than half of the reported plane strain fracture toughness.
\end{abstract}




\section{Introduction}

Sandwich structures with thin high-strength skins bonded to a honeycomb or foam core are widely used as lightweight, high-performance structural members. Many secondary aircraft components such as flaps, control surfaces and floor panels are based on such a construction. The general design principles of sandwich panels in terms of the skin/core contributions to their mechanical performance are well known $(1,2)$. The skins carry most of the bending, twisting and in-plane loading. The core, on the other hand, separates and stabilizes the skins in order to reach the desired panel bending stiffness and load-bearing capacity.

Since the 1940's, sandwich panels have been made from many different materials including metals, polymers, ceramics and their composites. Recently, new opportunities are arising for engineering applications of metallic honeycomb materials. Novel and improved manufacturing processes have beneficially affected performance and cost. Until recently, honeycomb panels could only be used at low to intermediate temperatures because skins were typically attached to the core using adhesives. The development of both liquid-phase bonding and solid-state bonding techniques for superalloys and their implementation in the production of superalloy honeycomb panels has dramatically increased the upper temperature limit for this class of materials. Higher levels of understanding of basic mechanical, thermal and acoustic properties have also been developed in conjunction with associated design strategies. Brazed superalloy honeycomb panels are under development for the thermal protection system of next-generation reusable launch vehicles. These vehicles will use the honeycomb panels as an active and load-bearing member of the primary structure. The panels will be subject to repetitive dynamic stresses, caused by mechanical, thermal and acoustic loading. Such alternating loads may cause premature failure even though they are well below the static design load. One of the most important properties with respect to long-term cyclic loading is cyclic fatigue crack growth resistance. However, crack initiation and propagation in both core and skin materials subject to dynamic loads is still relatively unexplored and basic knowledge and test procedures are yet to be developed.

Ashby and Gibson (1) and Shipsa et al. (3) independently show that the fatigue crack growth rate, $d a / D N$, in core materials, such as foam, increases rapidly with the applied stress intensity range, $\Delta K$. The fatigue crack growth behavior is well-described by the Paris-law:

$$
\mathrm{da} / \mathrm{dN}=\mathrm{C} \Delta \mathrm{K}^{\mathrm{m}}
$$

However, the values found for $m$ are extremely high compared to the values measured for bulk materials. $m$ has a value of 10 for polyurethane foam, 13 for phenolic foam, and 15 for polyisocyanurate foams (1). Their observations and recent findings on the fatigue crack growth behavior in both superalloy and aluminum honeycomb panels (4) lead us to believe that the fatigue crack growth resistance of standard light-weight honeycomb panels will mainly be governed by the skin.

One of the most prominent features of the skin is its small thickness. Modern light-weight honeycomb panels can have skins with a thickness as low as only $0.08 \mathrm{~mm}$ (4). This is about 10 times lower than the thickness for which fatigue crack growth data have been reported in literature thus far. Broek and Schijve (5) were amongst the first to report on the effect of 
sheet thickness on crack propagation rate. They found that, for 2024-T3 alclad sheet, cracks grow faster as the material thickness increases from $0.6 \mathrm{~mm}$ to $4 \mathrm{~mm}$. Puigh et al. (6) compared the crack propagation rate in standardized Ti-alloy specimens and in foil specimens with a thickness of $0.76 \mathrm{~mm}$ at room temperature. They found little dependency of crack growth rate on material thickness. James et al (7) also found little dependency of room temperature fatigue crack propagation rate in type 304 stainless steel on material thickness. Jack and Price (8), on the other hand, showed that for mild steel both crack initiation and crack growth were more rapid as the material thickness decreased from $23 \mathrm{~mm}$ to $1 \mathrm{~mm}$.

This paper reports on the elevated temperature fatigue crack growth behavior in Inconel 718 foil with a thickness of $250 \mu \mathrm{m}$. The principal goals of the paper are to describe the technique used for cyclic crack growth rate testing of the foil and to report cyclic fatigue crack growth rates as a function of test temperature.

\section{Experimental procedure}

\section{Material}

The Inconel 718 alloy foil used for the study was purchased from Goodfellow Corporation (Berwyn, PA). The foil had a nominal thickness of $250 \mu \mathrm{m}$. Rectangular specimens with a width of $31.75 \mathrm{~mm}$ were cut from the as-received foil using a bladed cutter. A starter notch was electro discharge machined in the center of the specimens. The center notch had an overall length of $2.0 \mathrm{~mm}$ and a height of $0.1 \mathrm{~mm}$. Some relevant mechanical properties of the foil are given in Table I.

Table I Room temperature mechanical properties of Inconel 718 foil

\begin{tabular}{c|c|c} 
Yield stress $(0.2 \%)$ & Tensile strength & Failure strain \\
\hline $470 \mathrm{MPa}$ & $920 \mathrm{MPa}$ & $40 \%$
\end{tabular}

\section{Experimental set-up}

All fatigue crack growth experiments were performed on an MTS servo-hydraulic load frame equipped with face loading grips. Uniform loading of the foil specimens was achieved by allowing the upper grip to pivot on a hemispherical bearing. Fatigue pre-cracking and the actual crack growth experiments were performed under load control using a tension-tension sinusoidal waveform at a frequency of $2 \mathrm{~Hz}$ and a stress ratio $\sigma_{\min } / \sigma_{\max }=0.1$. The fatigue pre-cracking was done at room temperature using a maximum fatigue stress, $\sigma_{\max }$, of 300 MPa. Crack growth along the face of the specimens was monitored using an optical microscope attached to a digital micrometer. The measuring system had a resolution of $0.002 \mathrm{~mm}$ and a repeatability of $0.005 \mathrm{~mm}$. Fatigue pre-cracking was performed until initial fatigue cracks, extending approximately $0.2 \mathrm{~mm}$ beyond the machined notch, were obtained. Once a starter crack was obtained, specimens were subjected to fatigue loading at the different test temperatures (room temperature, $400{ }^{\circ} \mathrm{C}$ and $550^{\circ} \mathrm{C}$ ) between stresses of 300 $\mathrm{MPa}$ and $30 \mathrm{MPa}$. A two-zone furnace was used for the elevated temperature testing. The furnace temperature was controlled by two type $S$ thermocouples entering from the side of 
the furnace. Specimens were typically heated to the desired test temperature in 15 minutes and held at temperature for 5 minutes prior to the start of a loading block. At the end of each loading block, the load was reduced, the furnace was shut down and the crack length measured. Tests were stopped at the onset of macroscopic plastic yielding in the foil. This typically occurred at crack lengths, $a$, of around $12 \mathrm{~mm}$. This corresponds to a crack length to width ratio, $a / W$, of 0.35 .

\section{Data analysis}

It is commonly accepted that, for a given material and set of test conditions, the cyclic crack growth behavior can be described by the relationship between cyclic crack growth $d a / d N$ and stress intensity range $\Delta K$. Liu et al. (9) studied the crack growth behavior of Inconel 718 at $650{ }^{\circ} \mathrm{C}$. They found that its creep crack growth is controlled by stress intensity factor regardless of load level, loading change and crack growth history. They concluded that elastic deformation is predominant throughout the crack growth of Inconel 718 at temperatures up to $650{ }^{\circ} \mathrm{C}$. It is therefore our belief that $\Delta K$ is a sufficiently accurate parameter to describe the driving force for fatigue crack growth at temperatures below 650 ${ }^{\circ} \mathrm{C}$. The applied stress intensity range $\Delta K$ was calculated in accordance with ASTM 647 "Standard Test Method for Measurement of Fatigue Crack Growth Rates":

$$
\Delta \mathrm{K}=\frac{\Delta \mathrm{P}}{\mathrm{B}} \sqrt{\frac{\pi \mathrm{a}}{2 \mathrm{~W}} \sec \frac{\pi \mathrm{a}}{2 \mathrm{~W}}}
$$

with $\quad \Delta \mathrm{P}: \quad$ the applied load range

B: the thickness of the material $(0.25 \mathrm{~mm})$

W: the width of the material $(31.75 \mathrm{~mm})$

To obtain crack growth rates from crack length, $a$, versus cycles, $N$, data, a simple and generally suitable approach is to calculate straight-line slopes between data points. The growth rate for a segment ending at point $j$ is given by:

$$
\frac{d a}{d N_{j}}=\frac{a_{j}-a_{j-1}}{N_{j}-N_{j-1}}
$$

The corresponding $\Delta K$ is calculated from the average crack length during the interval.

\section{Results and Discussion}

During the pre-cracking and the actual fatigue crack growth experiments, the lengths of the cracks growing from both sides of the center-notch were very close. The maximum difference in crack lengths measured at both sides of the center notch was typically less than $5 \%$. This is indicative of a homogeneous stress distribution in the foil specimens. Figure 1 gives some examples of the evolution of crack length, $a$, with number of fatigue cycles, $N$. It is obvious that fatigue crack growth is faster at $550^{\circ} \mathrm{C}$ than at room temperature and that the fatigue cracks grow at the same rate at both sides of the notch. 


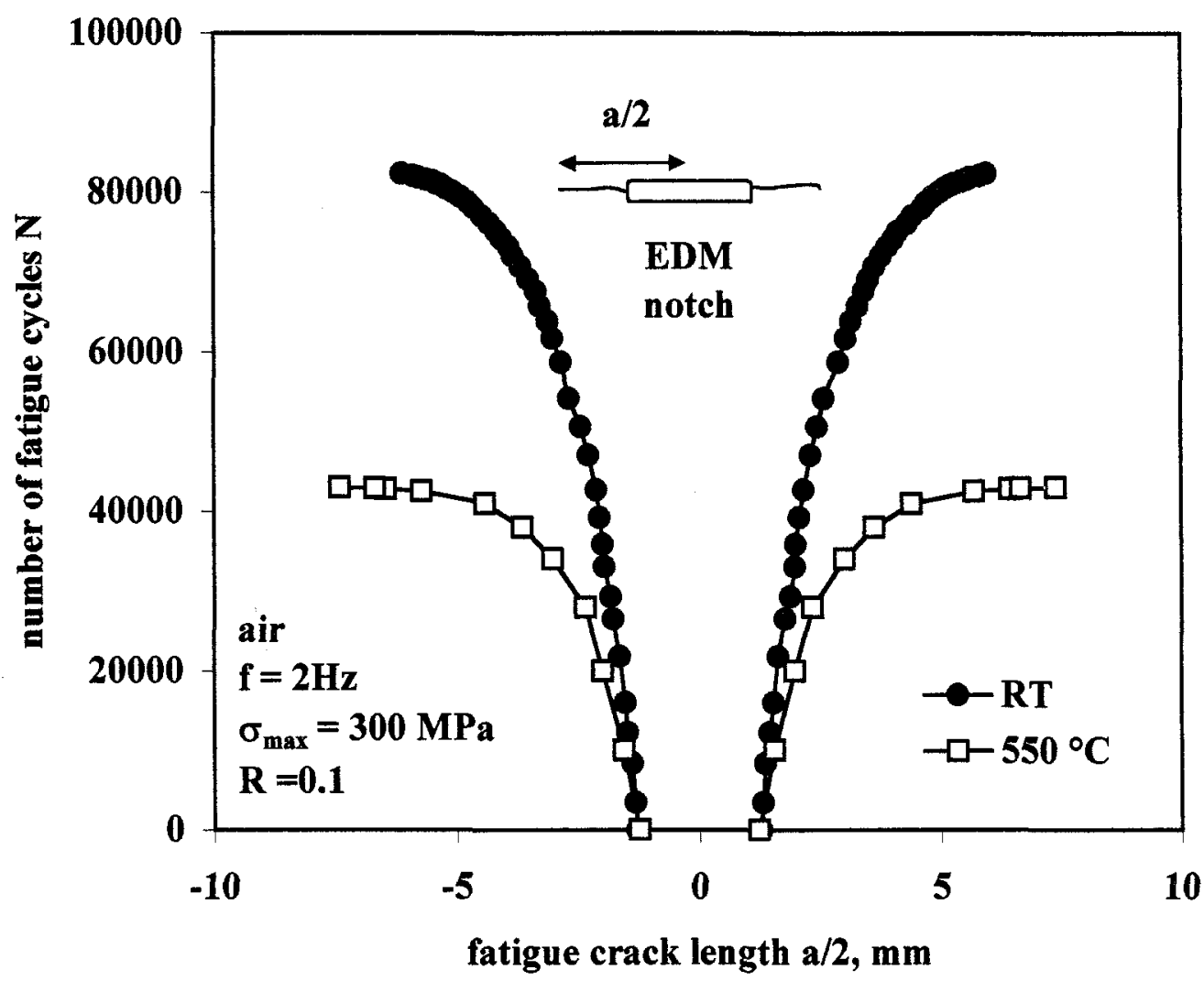

Figure 1: Experimentally measured relationships between the length of the cracks growing from both sides of the notch, $a / 2$, and the total number of fatigue cycles, $N$.

Figure 2 compares the experimentally measured relationships between fatigue crack growth rate, $d a / d N$, and applied stress intensity range, $\Delta K$, at room temperature, $400^{\circ} \mathrm{C}$ and $550^{\circ} \mathrm{C}$. The fatigue crack growth behavior is well described by the Paris law and the fatigue crack growth rates increase with an increase in temperature. Table II gives the best-fit values for the Paris-law parameters, $C$ and $m$. The best-fit values for $m$ are quite high compared to what is typically reported for fatigue crack growth in Inconel 718. Xie (10) reported fatigue crack growth data in Inconel 718 at $360^{\circ} \mathrm{C}, 550^{\circ} \mathrm{C}$ and $650^{\circ} \mathrm{C}$; the corresponding values for $m$ were 3.1, 3.0 and 2.5, respectively. James and Mills (11) studied the fatigue crack growth behavior of seven different types of Inconel 718 at five different test temperatures. For applied stress intensity ranges varying between roughly 20 and $70 \mathrm{MPa} \mathrm{m}{ }^{1 / 2}$, they reported best-fit values for $m$ between 2.5 and 4.5. 


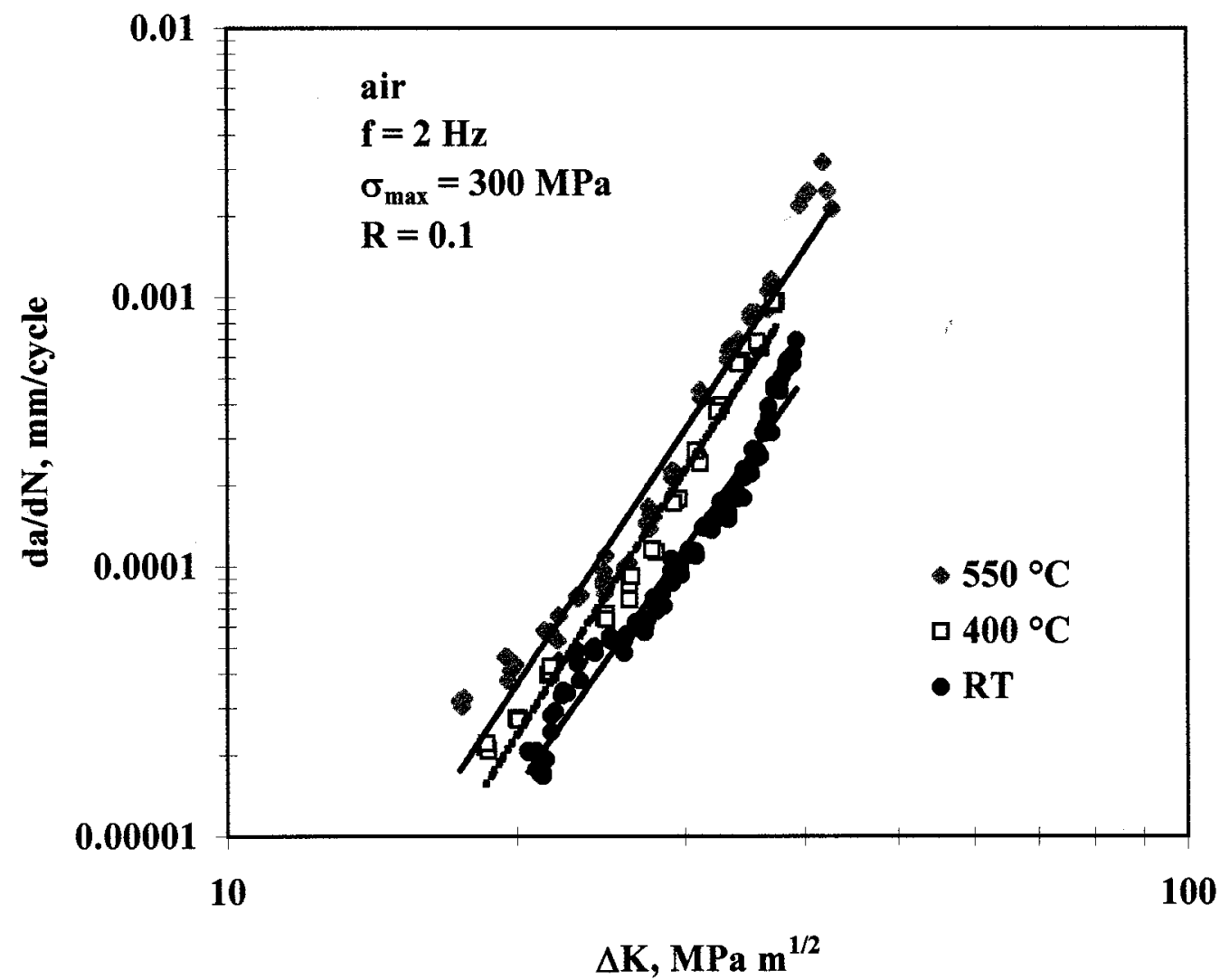

Figure 2: Experimentally measured relationship between applied stress intensity range, $\Delta K$, and fatigue crack growth rate, $d a / D N$, for Inconel 718 foil at RT, $400{ }^{\circ} \mathrm{C}$ and $550^{\circ} \mathrm{C}$.

Table II Comparison between the values for the Paris-law constants $(C$ and $m)$ for $250 \mu \mathrm{m}$ thick foil and values for thicker forms of material (thickness between 7.6 and $12.7 \mathrm{~mm}$ ).

\begin{tabular}{c|c|c|c|c} 
& \multicolumn{3}{|c|}{ current investigation } & literature $(10,11)$ \\
\hline temperature & RT & $400^{\circ} \mathrm{C}$ & $550^{\circ} \mathrm{C}$ & RT to $650^{\circ} \mathrm{C}$ \\
\hline$C$ & $4.910^{-12}$ & $1.410^{-12}$ & $1.510^{-12}$ & \\
\hline$m$ & 5.1 & 5.6 & 5.7 & 2.5 to 4.5
\end{tabular}

Although more experiments need to be "conducted before a definitive conclusion can be drawn, it appears that fatigue crack growth in thin Inconel 718 foil exhibits a much higher stress intensity range dependency than fatigue crack growth in thicker forms of material. In thin foils, fatigue crack growth also becomes unstable at much lower stress intensity values than in thicker material. James and Mills (11) conducted fatigue crack growth experiments on Inconel 718 using applied stress intensity ranges $\Delta K$ as high $90 \mathrm{MPa} \mathrm{m}{ }^{1 / 2}$ without crack growth becoming unstable. For the Inconel 718 foil, fatigue crack growth becomes unstable at stress intensity ranges as low as $35 \mathrm{MPa} \mathrm{m}{ }^{1 / 2}$. 
Although values of $m$ of 5 and higher are somewhat uncommon for ductile metals, they are often observed for fatigue crack growth in brittle materials such as ceramics (12). This observation together with the fact of unstable crack growth at low $\Delta K$ led us to believe that one of the possible explanations for the high fatigue crack growth rates in Inconel 718 foil might be a low fracture toughness.

The dependence of fracture toughness upon material thickness is schematically given figure $3(13,14)$. Beyond a certain thickness, $B_{0}$, a state of plane strain prevails and toughness reaches its plane strain value, $K_{I C}$. At a thickness $B_{45}$, the toughness reaches it highest level, the plane stress fracture toughness. For a thickness below $B_{45}$, there is uncertainty about the toughness. In some cases the toughness remains approximately equal to the plane stress fracture toughness. In other cases the toughness decreases strongly with decreasing thickness. This is because, in very thin sheets, fracture can be accomplished by plastic thinning in front of the crack, followed by shear fracture. A thin sheet is not constrained from contraction in the thickness direction and the volume of plastically deformed material scales with the thickness. Since the volume of plastically deformed material is a measure of the plastic work accompanying fracture, the fracture toughness scales with the thickness (14). This is for example one reason that metallic foils, such as household aluminum foil, can be so easily torn.

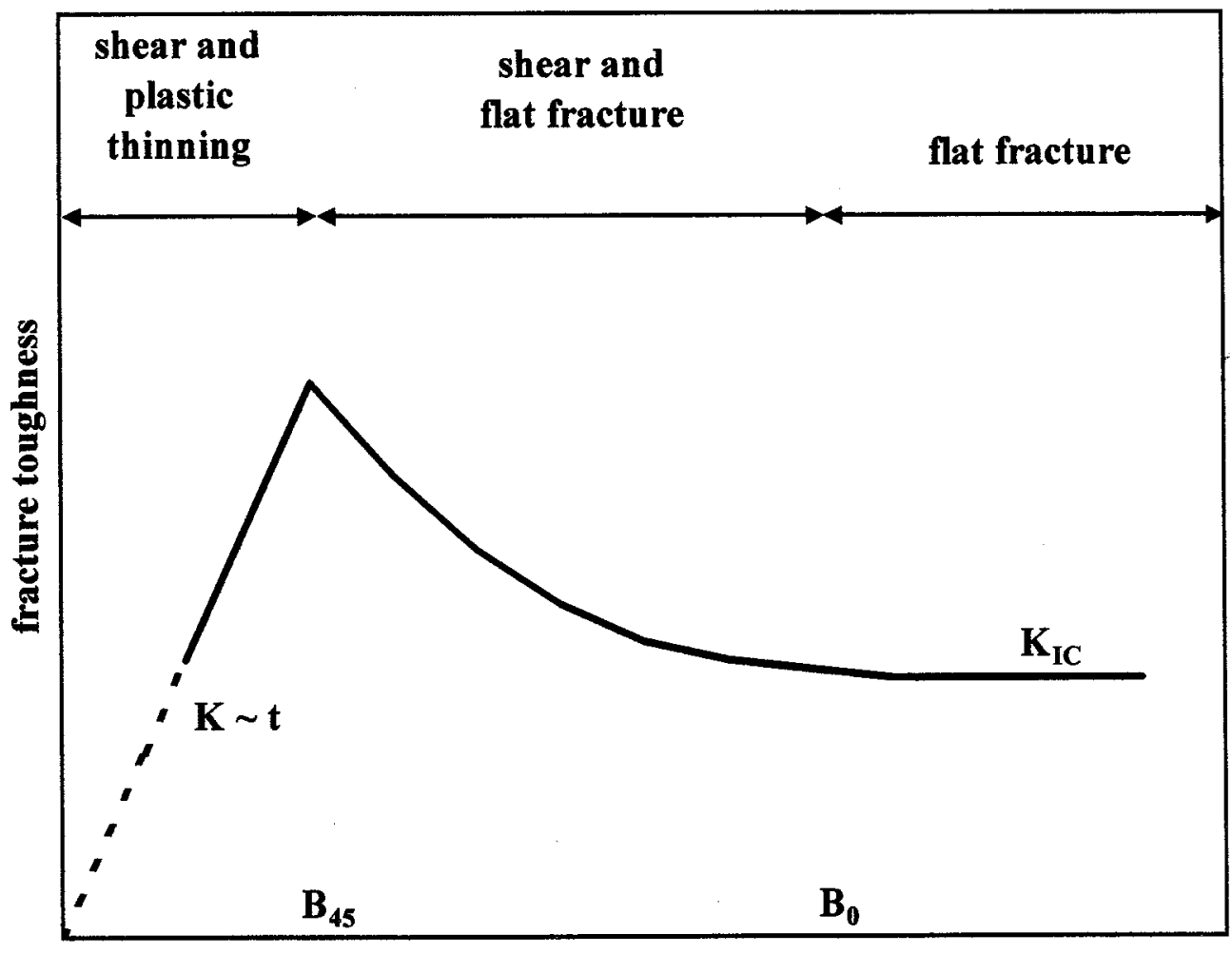

thickness

Figure 3: Fracture toughness as a function of material thickness.

The fracture toughness of the Inconel 718 foil was determined and compared with the fracture toughness values given in the literature for thicker Inconel 718 material. The specimens used to determine the fracture toughness were identical to the ones used for the 
fatigue crack growth experiments. Prior to fracture toughness testing, fatigue cracks were grown from a center-notch. After pre-cracking, the specimen was loaded until growth occurred. The fracture toughness values for the foil were determined using the secant method specified by ASTM 399 "Standard Test Method for Plane Strain Fracture Toughness of Metallic Materials". Figure 4 gives some examples of the measured relationships between load and displacement during fracture toughness testing of the foil. Table III compares the measured fracture toughness measured for the foil at different temperatures and compares them to values for thicker forms of material given in literature. Mills (15) and Mills and Blackburn (16) determined the plane strain $J_{I C}$ and $K_{I C}$ fracture toughness of different Inconel 718 materials at room temperature, $427^{\circ} \mathrm{C}$ and $538^{\circ} \mathrm{C}$. The specimens used for the investigation were compact tension specimens with a thickness of 12.6 to $14.7 \mathrm{~mm}$. The reported values range from $82 \mathrm{MPa} \mathrm{m}^{1 / 2}$ at $538{ }^{\circ} \mathrm{C}$ for material from a $50 \mathrm{~mm}$ bar to 131 $\mathrm{MPa} \mathrm{m} \mathrm{m}^{1 / 2}$ for plate material at $24^{\circ} \mathrm{C}$. It is obvious that the fracture toughness of the Inconel 718 foil is substantially lower than the fracture toughness found for thicker Inconel 718 specimens.

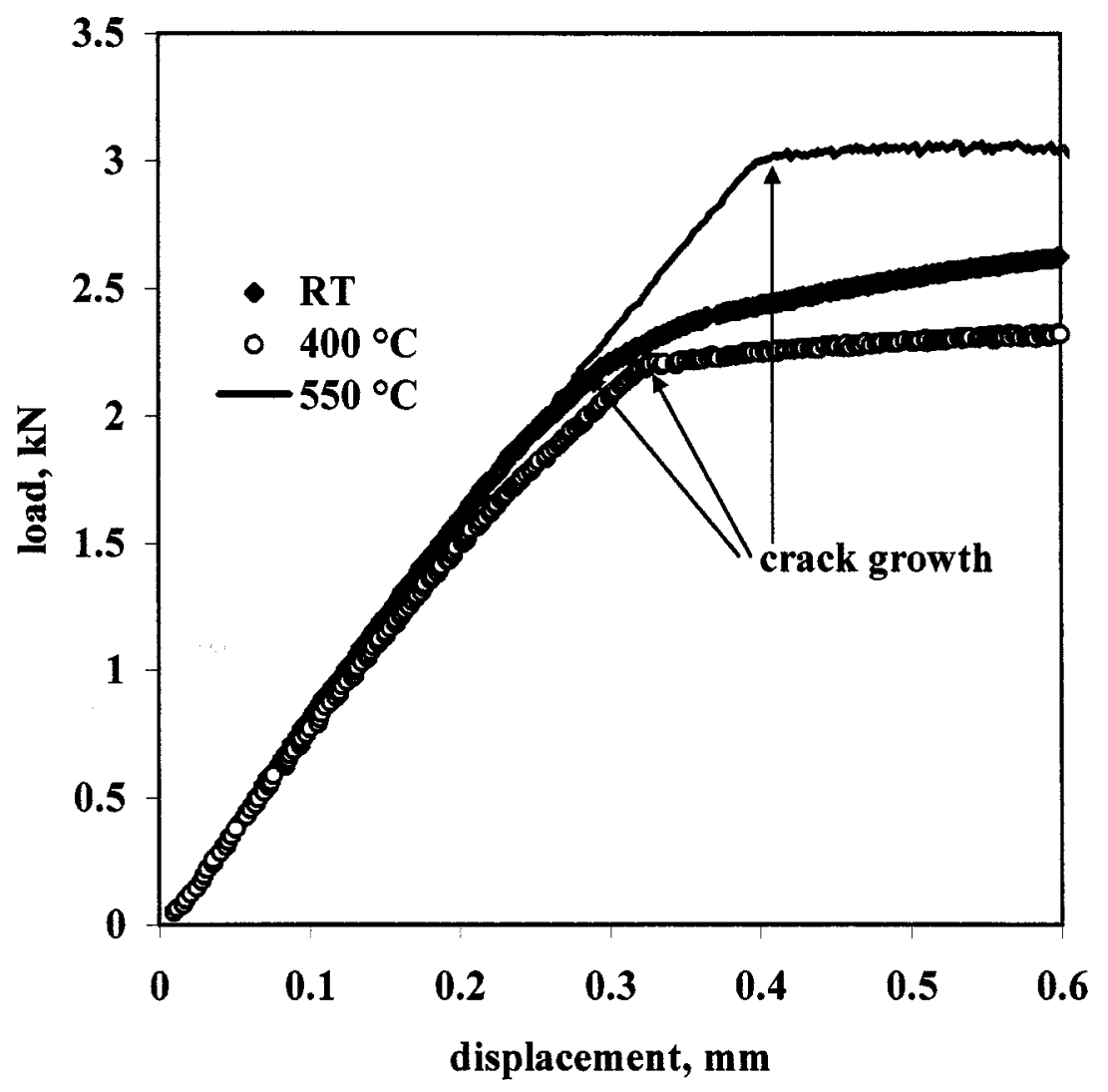

Figure 4: Relationship between load and displacement measured during fracture toughness testing of Inconel 718 foil. The arrows indicate the onset of crack growth. 
Table III Comparison of the fracture toughness of $250 \mu \mathrm{m}$ thick Inconel 718 foil and the fracture toughness of Inconel 718 material with a greater thickness.

\begin{tabular}{c|c|c|c|c} 
& \multicolumn{3}{|c|}{ current investigation } & literature (16) \\
\hline temperature & $\mathrm{RT}$ & $400{ }^{\circ} \mathrm{C}$ & $550^{\circ} \mathrm{C}$ & RT to $550^{\circ} \mathrm{C}$ \\
\hline fracture toughness, $\mathrm{MPa} \mathrm{m}^{1 / 2}$ & 38 & 33 & 34 & 82 to 131
\end{tabular}

It should be noted that Table III compares fracture toughness values that have been determined using different types of specimens, different test techniques and different Inconel 718 batches and that all these differences might have an effect on the measured fracture toughness. It is, however, our belief that the possible effect of differences in test techniques and material is unlikely to account for the dramatic difference between the fracture toughness of Inconel 718 foil and more thick material. In our opinion, the results presented in this study warrant a more systematic investigation of fracture and fatigue crack growth in thin Inconel 718 foils.

\section{Conclusions}

Fatigue crack growth rates, $d a / d N$, in $0.25 \mathrm{~mm}$ thick Inconel 718 foil increase very strongly with an increase in the applied stress intensity range, $\Delta K$. The values for the Paris-law exponent $m$ are higher than 5 .

A possible explanation for the strong stress intensity range dependency is the low toughness of the investigated Inconel 718 foil material. The measured fracture toughness value of about $35 \mathrm{MPa} \mathrm{m}{ }^{1 / 2}$ is less than half of the plane strain fracture toughness reported for thick Inconel 718 specimens.

\section{References}

1. L.J. Gibson and M.F. Ashby, Cellular solids: structure and properties (Cambridge University Press, 1997).

2. T. Bitzer, Honeycomb Technology (Chapman \& Hall, 1997).

3. A. Shipsa, M. Burman and D. Zenkert, "Interfacial fatigue crack growth in foam core sandwich structures", Fatigue and Fracture of Engineering Materials and Structures, 22 (1999), 123-131.

4. E. Vanswijgenhoven and J. Holmes, unpublished results.

5. D. Broek and J. Schijve, "The influence of sheet thickness on crack propagation", Aircraft Engineering, (1966), 31-33.

6. R.J. Puigh et al., "Miniaturized fatigue crack growth specimen technology and results", Journal of Nuclear Materials, $103 \& 104$ (1981), 1501-1504.

7. L.A. James, J.L. Straalsund and R.E. Bauer, "Optimization of fatigue crack growth testing for first wall materials development evaluation", Journal of Nuclear Materials, 85\&86 (1979), 851-854.

8. A.R. Jack and A.T. Price, "Effects of thickness on fatigue crack initiation and growth in notched mild steel specimens", Acta Metallurgica, 20 (1972), 857-866.

9. C.D. Liu et al., "Creep crack growth behaviour of alloy 718", Superalloy 718, 625 and Various Derivatives (The Minerals, Metals \& Materials Society, 1991), 537-548. 
10. J.Z. Xie, "Low cycle fatigue and fatigue crack growth behaviors of alloy IN718", Superalloy 718,625 and Various Derivatives (The Minerals, Metals \& Materials Society, 1991), 491-500.

11. L.A. James and W.J. Mills, "Effect of heat-treatment and heat-to-heat variations in the fatigue crack growth response of alloy 718", Engineering Fracture Mechanics, 22 (1985), 797-817.

12. S. Suresh, Fatigue of materials (Cambridge university press, 1991), 403-456

13. D. Broek, Elementary engineering fracture mechanics (Sijthoff \& Noordhoof, 1978), 91114.

14. T. H. Cortney, Mechanical behavior of materials (McGraw-Hill, 2000), 421-428.

15. W.J. Mills, "The effect of heat-treatment on the room temperature and elevated temperature fracture toughness response of alloy 718", Transactions of the ASME, 102 (1980), 118-126.

16. W.J. Mills and L.D. Blackburn, "Fracture toughness variations in alloy 718", Transactions of the ASME, 110 (1988), 286-293. 